Institute of $\mathbf{F}_{\text {ood and }} \mathbf{A}$ gricultural $\mathbf{S}_{\text {ciences }}$

\title{
Producing Peanuts for the Fresh Market ${ }^{1}$
}

\author{
E. B. Whitty ${ }^{2}$
}

While the vast majority of peanuts grown in the United States are dried before being processed and eaten as roasted nuts, peanut butter, in candy or other products, many consumers enjoy raw or boiled peanuts that are not dried to any extent before processing. Production of fresh market peanuts, also referred to as 'green' or 'boiling' peanuts, varies widely as to size of operation and cultural practices. A homeowner may grow a few plants in the garden for family use, or a small farmer may grow, harvest, and market a crop in his local area with little or no additional help, while large commercial producers may provide peanuts to supermarkets, roadside stands, and to food processors that can the peanuts after they are boiled. Consumers of boiled peanuts generally prefer fresh green peanuts rather than dry peanuts that have been pressure cooked or frozen green peanuts that have been boiled. These substitutes are occasional alternatives when fresh green peanuts are not available.

Florida is a major producer of fresh market peanuts because of its long growing season, and sandy soils that are conducive to peanuts having bright hulls, an important feature for some markets. Most of the commercial acreage is in central Florida, but peanuts are planted for early spring harvest in warm areas of southern counties. Most of the northern and panhandle counties have farms that harvest various quantities of fresh market peanuts.

Producing peanuts for the fresh market requires planning and facilities that do not apply to production for the dry markets. Nor does conventional marketing apply to the fresh market--more labor will be required, and a packing shed and coolers will be needed for larger operations that do not ship the green peanuts immediately after harvest.

There has been limited research on producing fresh market peanuts in Florida, so the following comments and suggestions are based to some extent on practices used for dry peanuts, and on observations of practices used by some producers of green peanuts. Because target markets and locations are highly variable, production practices are also variable and a grower may devise practices that are unique to his operation.

Prior to the end of the quota system of the federal peanut program in 2002, peanuts harvested for the fresh market were not subject to quotas, but commercial acreage still had to had to be reported to the local USDA Farm Service Agency Office. The provisions of the new 2002 Farm Bill may include a

1. This document is SS-AGR-190, one of a series of the Agronomy Department, Florida Cooperative Extension Service, Institute of Food and Agricultural Sciences, University of Florida. Published March 2003. Visit the EDIS Web Site at http://edis.ifas.ufl.edu.

2. E. B. Whitty, professor, Agronomy Department; Florida Cooperative Extension Service, Institute of Food and Agricultural Sciences, University of Florida, Gainesville FL 32611.

The use of trade names in this publication is solely for the purpose of providing specific information. UF/IFAS does not guarantee or warranty the products named, and references to them in this publication does not signify our approval to the exclusion of other products of suitable composition.

The Institute of Food and Agricultural Sciences is an equal opportunity/affirmative action employer authorized to provide research, educational information and other services only to individuals and institutions that function without regard to race, color, sex, age, handicap, or national origin. For information on obtaining other extension publications, contact your county Cooperative Extension Service office. Florida Cooperative Extension Service/Institute of Food and Agricultural Sciences/University of Florida/Christine Taylor Waddill, Dean. 
base and other benefits for previous and current production of green peanuts, which can be determined by contacting the local FSA office.

\section{Markets}

The intended market should be identified and evaluated to quality and volume needs as the first step before entering into fresh market peanut production. It may be possible to enter into contracts and agreements with buyers, but the potential grower should at least have assurance that his product will be acceptable and in demand at a price that he will need for profitability. Market windows and varieties are often of vital importance, and meeting quality standards of the buyer should be a part of any plan. A marketing plan and complete budgets should be developed before planting.

If the peanuts are to be sold to supermarkets or other establishments that will retail them as raw fresh peanuts where the ultimate consumer may demand bright hulls with little or no visible damage, then it may be necessary to use hand harvesting. If the initial buyer is going to boil and then sell the peanuts to the ultimate consumer, then it may be possible to harvest with a conventional peanut combine. Bruising and damage to the hulls will occur with machine harvesting which detracts from a desirable visual appearance and may cause them to be more perishable, consequently reducing shelf life. But bruising and hull damage may not be as important if the peanuts are boiled relatively soon after harvest as the hull may darken to some extent when boiled, and deterioration may not develop from the bruises. They may then be sold relatively soon at roadside or other stands, or they may be canned for later sale. Machine harvesting also results in more contamination with trash (attached peg stems, roots, vine parts, and other debris) and young, undeveloped pods. A picking line or conveyor belt with hand removal of undesirable material would be needed for both methods of harvest. If hand harvesting is planned, then considerably more labor will be required than for machine harvesting, but less labor should be needed at the packing shed for the same volume of peanuts. Prices for hand-harvested peanuts may be higher than those that are machine harvested because of better visual appearance and shelf life.
Machines to specifically harvest green peanuts without causing extensive pod damage have been built and used to some extent, but have had only limited acceptance in Florida. It is possible that future machines will be faster and more efficient than hand picking, but may also result in limited pod damage. Such machines would have a major positive impact on the industry.

After processing--which may include washing--the raw peanuts should be stored in a cooler until they are transferred to the buyer. For preservation of taste and less deterioration, the storage period should be as short as possible. Market windows and other marketing considerations may also affect the decision as to production plans.

\section{Production Practices}

Many of the production practices used for dry peanuts are identical or very similar to those used for fresh market peanuts, with harvest and post-harvest processing being major differences. Market windows are shorter and much more important for the perishable fresh market peanuts than for dry peanuts, and this calls for variations in planting dates and often areas of production. Certain types and varieties are popular for fresh market peanuts.

\section{Varieties}

While any peanut variety can be used for the fresh market, the valencia and virginia market types are favored by most consumers. Valencia varieties have a desirable flavor, and three to four seed per pod. Generally the seed coat (testa) is red. Virginia varieties produce large seed and also have a desirable flavor. Growers like the valencia type because they mature early and are easier to hand harvest because the pods are concentrated near the tap root. Virginia varieties have large kernels and those that mature early are generally preferred. An extra large peanut, known by various names that usually include the word 'giant' in the name, such as African Giant, has also been grown successfully in Florida. These varieties are probably derived from a breeding line known as Jenkin's Jumbo. Extra large peanuts often have an above-average percentage of unfilled pods. Gypsum applications are very important for proper 
pod filling of the extra large peanuts, as well as for bright hulls.

Popular valencia varieties include New Mexico Valencia A, New Mexico Valencia C, McRan, and Georgia Red. A recent release, Georgia Valencia, may also become popular as it has performed well in variety tests. A popular virginia market-type variety has been NC 7, an early-maturing and large-seeded peanut. Gregory is a more recent release and has similar maturity to $\mathrm{NC} 7$, but produces even larger seed. Gregory has produced good yields in Florida tests, but there is little or no information as to how suitable it may be for the fresh market. Gregory also has better tomato spotted wilt virus (TSWV) resistance than other virginia varieties.

Varieties grown for the dry market have considerable variation in tolerance to various diseases, particularly to TSWV. There have been a few isolated instances of TSWV damage to peanuts being grown for the fresh market, and if this disease becomes widespread, variety selection would become more limited. Areas of production and planting dates could also be affected.

Traditionally seed of the valencia and virginia varieties grown for the fresh market have not been as easily available as the seed of runner varieties. Thus potential growers should locate sources of the desired varieties well before the expected planting date. Due to changes in the peanut program in the 2002 Farm Bill, local production of seed of the desired varieties may become more common.

\section{Planting Dates}

As with many other perishable crops, prices for fresh market peanuts tend to be higher in the early season when supplies are limited. In an effort to obtain these higher prices, more risks are often taken by planting peanuts earlier than normal and/or in warmer locations in southern Florida. Frost or freeze damage is a danger, but even extended periods of cool weather will substantially slow seed germination and growth of the plants and also delay peanut maturity. Reduced yields would be expected. In such situations, the grower must decide the level of risk that would be acceptable in exchange for the price that may be expected. A general recommendation is to plant peanuts only after the danger of frost has passed, and the maximum soil temperature at the planting depth has been above $65^{\circ} \mathrm{F}$ for three or more consecutive days. Wetter soils are generally cooler than more well-drained soils and are slower to warm up in the spring. Any irrigation that is needed should be applied a few days before planting so that the soil temperatures have an opportunity to recover. Rain or irrigation soon after planting under cool conditions can delay seed germination and early growth of the peanuts.

Peanuts may be planted in the mid- to late summer in an effort to extend the marketing season of fresh peanuts into the late fall and early winter. Similar risks as with early-planted peanuts can be expected for late-planted peanuts in that early cool weather in the fall will delay maturity of the peanuts and limit yields. The peanuts should be planted early enough so that they would normally be mature before the first frost of the fall. It is also likely that insect and disease pressures will be high at planting in the mid- to late summer. Again the grower must decide on how much risk would be acceptable for the price he expects to receive.

In areas where TSWV is common, early or late planting of peanuts for the dry market has resulted in greater losses to the disease than mid-season planting. Thus far TSWV has caused only isolated losses to peanuts being grown for the fresh market, but the disease has the potential to be devastating.

\section{Planting}

Use high-quality seed that has been tested and shown to have good germination and vigor. If good seed storage facilities are not available, wait until planting to take delivery of the seed. Use care in handling the seed as they are fragile and can be damaged by dropping or throwing bags of seed. Be sure that the planter does not damage the seed during planting.

Peanuts do not grow well in poorly-drained soils, so ditching for drainage may be needed in wetter locations. Rotation with a crop that is resistant to common pests of peanuts is highly desirable. Grass crops are usually excellent for use in crop rotations with peanuts. If possible, peanuts should not be 
grown on the same soil more than once every three to four years.

While little information is available on planting fresh market peanuts under strip or conservation tillage practices, it has been satisfactory for dry market peanuts. Strip or other conservation tillage programs can reduce land preparation time and the costs of growing peanuts. The incidence of TSWV has also been less under strip tillage. If peanuts are to be planted in the late winter or early spring in an effort to gain an early market, it may be advisable to use conventional tillage to prepare the land for planting because soil temperatures will usually be higher than with strip tillage. If conventional tillage is used and the soil is subject to wind erosion, it would be advisable to plant windbreaks of rye to prevent damage to the young plants from blowing sand.

Seed should be placed 2 inches apart in the row if single rows are used. Lower plant populations could result in more TSWV if the disease is common to the area. If twin rows are used, the same quantity of seed per acre as for single rows, or seed planted 4 inches apart, would be satisfactory. Twin rows often result in increased yields, but be sure harvesting procedures, including hand picking, are as efficient with twin rows as they are for single rows.

Planting depths are usually 1 1/2 -3 inches, with the greater depth being used on sandier soils that tend to dry quickly at the soil surface. The planter should firmly pack the soil around the seed to insure good contact and quick germination and emergence. To provide drainage, the top of the seed row should be level with, or slightly above, the row middle.

\section{Fertilization}

The general liming and fertilization recommendations for dry market peanuts should apply to fresh market peanuts. The target soil $\mathrm{pH}$ is 6.0, with lime being recommended when soil tests show the $\mathrm{pH}$ to be 5.8 or less. Unless there is a need to supply magnesium, calcic lime or calcium carbonate would be the preferred source of lime because of the importance of calcium to pod filling and hull brightness. If magnesium is needed, dolomite as the liming source would be the least expensive means of supplying magnesium, as well as increasing the soil $\mathrm{pH}$.

Follow fertilization recommendations that are based on results of a soil test. If no soil test results are available, a pre-plant fertilizer application that contains about 50 pounds per acre of $\mathrm{P}_{2} \mathrm{O}_{5}$ and 100 pounds per acre of $\mathrm{K}_{2} \mathrm{O}$ is suggested for sandy, well-drained soils. If the soil levels of phosphorus and potassium would be expected to be high because of fertilization of a previous crop, residual nutrients may be adequate for the peanuts and no direct fertilization would be required. While nitrogen fertilizer has seldom increased yields, many peanut farmers apply about 25 pounds of fertilizer nitrogen per acre to stimulate early growth. There is no research evidence that relates faster early growth to earlier maturity and harvest. If legumes, such as peanuts, beggarweed, hairy indigo, cowpeas, or other plants in the cowpea inoculation group have not been grown recently on the land, an inoculant should be added to the seed or seed furrow at planting. The inoculant supplies the nodule bacteria that allows nitrogen from the air to be incorporated into the peanut growth.

Boron should be a part of the fertilization program, especially for peanuts grown on sandy soils. About 1/2 pound of elemental boron should be applied in the pre-plant fertilizer or as a foliar spray by the time of first flowering. Manganese deficiency may occur if peanuts are grown on certain soils that have been limed to a $\mathrm{pH}$ of 6.2 or higher, and can be corrected with a foliar spray of manganese sulfate or other suitable material. While boron and manganese are more common, other micro-nutrient deficiencies may be noted under specific conditions, and can usually be corrected with the appropriate foliar spray.

As indicated above, calcium is a critical soil nutrient needed in peanut production, especially for pod filling and hull brightness. The calcium must be in the pegging and pod development zone for it to be effective because very little of the nutrient is translocated from the roots or other plant parts to the developing pods. To supply the needed calcium, gypsum should be applied at early bloom and before pegging. Dry, bagged gypsum may be banded (18-inch band) over the row at the rate of 400 pounds 
per acre for valencia and runner varieties, and 800 pounds per acre for the large-seeded virginia varieties. Large operators usually prefer to broadcast gypsum. If broadcast, and if the gypsum is a bulk source from electric power plants or phosphate mines, the rate should be at least double the banded rate. Also, bulk gypsum, which normally is less pure and has a higher moisture content than bagged gypsum, requires increased rates to get the same rate of calcium in the pegging zone. Thus a ton of bulk gypsum that is broadcast should supply approximately the same amount of calcium in the pegging zone as 800 pounds per acre of bagged gypsum that is banded.

\section{Pest Management}

Practices used to prevent nematode, weed, disease, and insect losses in peanuts grown for the dry market should apply to fresh market peanuts. Because the visual appearance needed for fresh market peanut consumers may be critical, it may be important to prevent pod damage or blemishes due to soil pests and diseases. Lesion and root knot nematodes, wire worms, lesser corn stalk borers, and the various pod rot diseases can be sources of these blemishes. Cultural practices and pesticides as recommended in the various pest control guides should be followed for the management of these pests. It is important to pay extra attention to the label instructions for the length of the pre-harvest interval for application of some pesticides, because green peanuts are harvested earlier than they would be for the dry market.

\section{Harvesting}

Due to the supply and demand during various marketing windows, variable consumer demands, maturity at harvest, higher labor requirements, and needed facilities, harvesting of green peanuts requires extensive planning and preparation.

\section{Maturity}

Since peanuts bloom and peg over a long period of time, all pods do not mature at the same time. Peanuts grown for the fresh market are normally harvested at an earlier stage of maturity than peanuts grown for the dry market, but there are no standards for maturity determination. The peanut maturity profile or hull-scrape technique has been very useful to predict and determine optimum maturity of dry peanuts, but thus far it or a comparable system has not been adapted for green peanuts. The consumer demand (or what the grower perceives to be desirable maturity) influences the time of harvest. Generally, the more mature the peanut, the more flavor it will have, but it will also absorb less salt during boiling, will be harder to shell and the kernels will be firm. The shell of more mature peanut pods is often not as bright as a less mature pod. Kernels that have not reached maturity will be soft and absorb more salt when boiled, which will enhance the flavor.

As indicated earlier, it would be difficult to always use days after planting as an absolute key to maturity, but it is still a useful criteria. The valencia varieties mature faster than other varieties with many early spring-planted crops being ready to dig at about 90 days after planting. The same varieties planted at a more optimum period in the late spring may be ready to harvest in 75 days because of higher temperatures during the growing season. On the other hand, it would take well over a 110 days for maturity for the same varieties planted during the winter or when temperatures are frequently below $50^{\circ} \mathrm{F}$. Virginia varieties will probably take about 20 days longer to mature than valencia varieties grown under identical conditions.

\section{Harvesting}

When the time of harvest has been selected, the peanuts may be pulled by hand, dug with a shovel or other tool, or dug with a conventional peanut digger. The digging method will be determined by the size of the operation and the marketing procedures. Hand picking can begin immediately after digging, but digging should not be so far ahead of picking that there is a risk of excessive drying, of rain, which may delay picking and darken the hulls, or of other delays that may affect the quality of the peanuts. If a conventional peanut combine is to be used to pick the peanuts, a few hours between digging and picking will allow the hulls to dry to some extent and not be bruised as badly by the combine. 
After picking, the peanuts should be moved as soon as practical to the packing shed. Here they can be washed and passed over a conveyor belt or picking line so that trash, damaged pods, and other debris and foreign matter can be removed by workers. The cleaned peanuts can then be placed in crates or other containers and placed in a cooler until they are shipped or sold. Peanuts are at their highest quality at the time of digging, and then deteriorate until they are consumed, but this deterioration will be much slower with proper handling and refrigeration. Less time between digging and consumption means a more satisfied consumer.

\section{Marketing}

As indicated earlier, there are no standard marketing procedures or quality standards for fresh market peanuts, so the producer and his buyer have to develop a mutually satisfactory arrangement for determining price and quality. Maturity, moisture content, uniformity, damage, foreign matter, and many other factors may enter into a quality determination. Dry peanuts are sold by weight and the quality is determined by standardized federal grading procedures, and if properly stored, deterioration is relatively slow. Green peanuts are sold by volume, usually by the bushel, and are quite perishable. Thus the marketing procedures for green peanuts must be efficient and move the peanuts from the field to the consumer as quickly as possible.

Most green peanuts are sold on a volume basis, but the intermediate buyer may resell them on a weight basis, either raw or boiled. This often brings up the question of how many pounds there are in a bushel of green peanuts. Again there are no standards, because the answer is affected by maturity, moisture content, and the size of the pods. For example, a bushel of valencia peanuts will weigh more than a bushel of virginia peanuts at equal maturity and moisture level, because of the smaller pods. Thus the most simple and accurate determination is to weigh a bushel, or portion thereof, of the peanuts in question. Longtime producers and buyers have developed agreements on the weight per bushel. For example, the weight of a bushel of valencia peanuts is usually accepted to be $30-35$ pounds. 